\title{
N-6 Polyunsaturated Fatty Acids and Risk of Cancer: Accumulating Evidence from Prospective Studies
}

\author{
Youngyo $\mathrm{Kim}^{1}$ and Jeongseon $\mathrm{Kim}^{2}, * \mathbb{C}$ \\ 1 Department of Food and Nutrition/Institute of Agriculture and Life Science, \\ Gyeongsang National University, Jinju 52828, Korea; youngyokim@gnu.ac.kr \\ 2 Department of Cancer Biomedical Science, Graduate School of Cancer Science and Policy, \\ National Cancer Center, Goyang 10408, Korea \\ * Correspondence: jskim@ncc.re.kr; Tel.: +82-31-920-2570
}

Received: 23 July 2020; Accepted: 17 August 2020; Published: 20 August 2020

\begin{abstract}
Previous studies on the association between polyunsaturated fatty acids (PUFAs) and cancer have focused on n-3 PUFAs. To investigate the association between intake or blood levels of n-6 PUFAs and cancer, we searched the PubMed and Embase databases up to March 2020 and conducted a meta-analysis. A total of 70 articles were identified. High blood levels of n-6 PUFAs were associated with an $8 \%$ lower risk of all cancers (relative risk $(R R)=0.92 ; 95 \%$ confidence interval (CI): 0.86-0.98) compared to low blood levels of n-6 PUFAs. In the subgroup analyses by cancer site, type of $\mathrm{n}-6$ PUFAs, and sex, the inverse associations were strong for breast cancer $(\mathrm{RR}=0.87 ; 95 \% \mathrm{CI}$ : $0.77-0.98)$, linoleic acid (LA) (RR $=0.91 ; 95 \%$ CI: 0.82-1.00), and women ( $R R=0.88 ; 95 \%$ CI: 0.79-0.97). In the dose-response analysis, a $2 \%$ and $3 \%$ decrease in the risk of cancer was observed with a $5 \%$ increase in blood levels of n-6 PUFAs and LA, respectively. Thus, there was no significant association between n-6 PUFA intake and the risk of cancer. The pooled RR of cancer for the highest versus lowest category of n-6 PUFA intake was 1.02 (95\% CI: 0.99-1.05). Evidence from prospective studies indicated that intake of n-6 PUFAs was not significantly associated with risk of cancer, but blood levels of n-6 PUFAs were inversely associated with risk of cancer.
\end{abstract}

Keywords: n-6 fatty acids; cancer; meta-analysis; prospective studies

\section{Introduction}

Polyunsaturated fatty acids (PUFAs) are long-chain fatty acids which include more than one double bond in their backbone and are classified as n-3 PUFAs and n-6 PUFAs, according to the position of the first double bond in the carbon chain [1]. Generally, PUFAs have been considered beneficial for human health because of their anti-inflammatory effects compared to other types of fatty acids, such as saturated or trans fatty acids [2]. However, existing evidence for the association between PUFAs and chronic disease has focused mostly on n-3 PUFAs [3]. The potential effect of n-6 PUFAs has received less attention, and results on the associations between n-6 PUFAs and disease risk have additionally been reported in studies focused on other types of fatty acids. Since high proportions of dietary n-6 PUFAs are found in the Western diet, which is spreading across the world [4], it is important to identify the association between n-6 PUFA intake and the risk of chronic disease, such as cancer.

Some studies have recommended reducing n-6 PUFA intake, pointing out that n-6 PUFAs, especially arachidonic acids (AAs), produce eicosanoids that can increase inflammatory disorders $[2,5]$. Most of the studies investigating the association between intake or blood levels of fatty acids and the risk of cancer have provided results by type of fatty acids, including n-6 PUFAs; however, to our knowledge, there has been no comprehensive meta-analysis exploring the association between $n-6$ PUFA intake and risk of all cancers since 1998 [6]. The meta-analysis published in 1998 found no 
evidence suggesting that high linoleic acid (LA) intake increases the risk of cancer [6]. A review evaluating the association between AA and the risk of cancer also concluded that AA was not associated with an increased risk of breast or prostate cancer [7]. It is not easy to compute the intake of specific fatty acids accurately [8], and misclassification often occurs [9]. Regarding PUFAs, the measurement of biomarkers may provide a more accurate assessment of intake because PUFAs are rarely endogenously synthesized [10]. Therefore, it is necessary to consider both intake and biomarkers of fatty acids when analyzing the association between PUFAs and the risk of disease. To clarify the association between the intake or blood levels of n-6 PUFAs and the risk of cancer, we conducted a systematic review and meta-analysis of prospective studies.

\section{Materials and Methods}

According to the Preferred Reporting Items for Systematic Reviews and Meta-Analyses (PRISMA) statement [11], two authors (Y.K. and J.K.) independently performed a literature search, study selection, data extraction, and quality assessment. Any discrepancies were addressed through reviewing the original articles and discussion.

\subsection{Literature Search and Study Selection}

We searched for eligible articles published up to March 2020 in the PubMed and Embase databases. The search terms were as follows: "(fat OR fatty acids) AND (cancer) AND (risk OR incidence)". To supplement the search, we reviewed the reference lists of previous reviews and the retrieved articles.

To be included in this meta-analysis, articles had to meet the following criteria: (1) prospective design (cohort or nested case-control); (2) intake of n-6 PUFAs or blood levels of n-6 PUFAs as the exposure of interest; (3) cancer as the outcome of interest; and (4) reporting of relative risks (RRs) and 95\% confidence intervals (CIs). If more than one article provided the RRs for risk of the same cancer site from the same cohort, the study including the largest population was selected for the meta-analysis.

\subsection{Data Extraction}

The following information was extracted: first author's surname, publication year, region of study, cohort name, dates of study period, sex and baseline age of subjects, number of cases and subjects/controls or person-time, types of cancer, types of n-6 PUFAs, RRs with corresponding 95\% CIs for all categories of n-6 PUFA intake or blood levels of n-6 PUFAs, and adjustment factors. We included the RRs that were maximally adjusted for potential confounders in the meta-analysis.

\subsection{Quality Assessment}

The study quality was evaluated using the Newcastle-Ottawa quality assessment scale [12]. This scale is based on 3 domains: selection of participants, comparability of study groups, and ascertainment of outcomes of interest. Studies with scores of 6 or less, 7 to 9, and 10 or higher (out of 13) were considered low, good, and high quality, respectively.

\subsection{Statistical Analysis}

The pooled RRs and 95\% CIs were calculated using the DerSimonian and Laird random-effects model [13]. Any results provided separately by sex, cancer stage, specific tumor sites (e.g., colon or rectal), or types of n-6 PUFAs were combined using a fixed-effects model and included in the main analysis. The separately reported RRs were used in the subgroup analysis by sex or types of $n-6$ PUFAs. We performed subgroup analyses by cancer site, type of n-6 PUFAs, and sex when data were available. When one article reported RRs of both all cancers and type of cancer (e.g., breast or prostate), we included RRs of all cancers in the main analysis. The RRs of type of cancer were used in the analysis by cancer site. 
A dose-response meta-analysis was carried out using the method described by Greenland and Longnecker [14-16]. The median or mean value for each exposure category (n-6 PUFA intake or blood levels of n-6 PUFAs) was assigned to the corresponding RR. We assumed that open-ended categories would have the same interval as the adjacent category. Furthermore, when n-6 PUFA intake was reported as density $(\mathrm{g} / \mathrm{kcal}$ or $\% / \mathrm{kcal})$, we converted these values to absolute intake $(\mathrm{g} /$ day) using the mean daily energy intake of the study participants, considering that fat provides nine calories per gram. We assessed a potential nonlinear relationship by means of restricted cubic splines with 3 knots at fixed percentiles $(10 \%, 50 \%$, and $90 \%)$ of the aggregated exposure. A $P$ value for nonlinearity was obtained by testing the regression coefficient of the second spline equal to zero [17].

Heterogeneity across studies was assessed using the $Q$ statistic [18] and quantified by the $I^{2}$ statistic [19]. To explore the robustness of the results, a sensitivity analysis that excluded one study at a time and pooled the remaining studies was conducted. Begg's [20] and Egger's [21] tests were performed to evaluate a publication bias. The $\alpha$ level of statistical significance was set at $p \leq 0.05$. All statistical analyses were conducted with STATA software version 14.2 (StataCorp, College Station, TX, USA).

\section{Results}

\subsection{Study Characteristics}

A total of 70 publications were eligible for meta-analysis of the prospective association between intake or blood levels of n-6 PUFAs and the risk of cancer [22-91]. The detailed process of study selection is presented in Supplementary Figure S1. Forty-one articles reported RRs for n-6 PUFA intake only $[22,23,25,29-31,33,34,36,37,40,44-46,48-50,53,54,57-60,63-66,69,72,75,77-81,83$, 85-87,90,91], 24 articles reported RRs for blood n-6 PUFA levels only [24,26-28,38,39,41,42,47,51,52, 55,56,61,62,67,68,70,71,74,82,84,88,89], and 5 articles provided RRs for both n-6 PUFA intake and blood n-6 PUFA levels [32,35,43,73,76]. The types of cancer could be summarized as follows: breast (23 articles and 17,546 cases) [22,26,27,32,34,38,45,46,50,54,55,62,69,71,74,77-79,81,82,84,87,88], prostate (17 articles and 39,038 cases) [22,40-43,52,56,61,64-66,68,72,73,76,86,89], colorectal (14 articles and 10,541 cases) $[28,29,33,35,37,48,49,57,59,60,63,67,70,91]$, pancreas ( 5 articles and 2403 cases) $[24,53,58,75,80]$, endometrium ( 3 articles and 1756 cases) [31,36,85], skin ( 3 articles and 36,819 cases) [23,39,44], and others (ovarian, lung, liver, lymphoma, and gastric; 6 articles and 2958 cases) [25,30,47,51,83,90]. Three articles provided RRs of any type of cancer [22,38,73]. All studies scored higher than 9 points on the quality assessment, indicating good quality, and the median value was 11 points.

\subsection{N-6 PUFA Intake}

Forty-six articles including 99,877 cancer cases investigated the association between n-6 PUFA intake and the risk of cancer $[22,23,25,29-37,40,43-46,48-50,53,54,57-60,63-66,69,72,73,75-81,83,85-87,90,91]$ (Supplementary Table S1). The pooled RR of any type of cancer for the highest versus lowest categories of n-6 PUFA intake was 1.02 (95\% CI: 0.99-1.05) (Figure 1). No evidence of publication bias was found by Begg's test $(p=0.15)$ or Egger's test $(p=0.24)$. We did not find any significant associations in the subgroup analyses by cancer site, type of n-6 PUFAs, or sex (Table 1). In the dose-response analysis, there was no significant linear $(p=0.06)$ or nonlinear $(p=0.92)$ association between $n-6$ PUFA intake and the risk of cancer. 


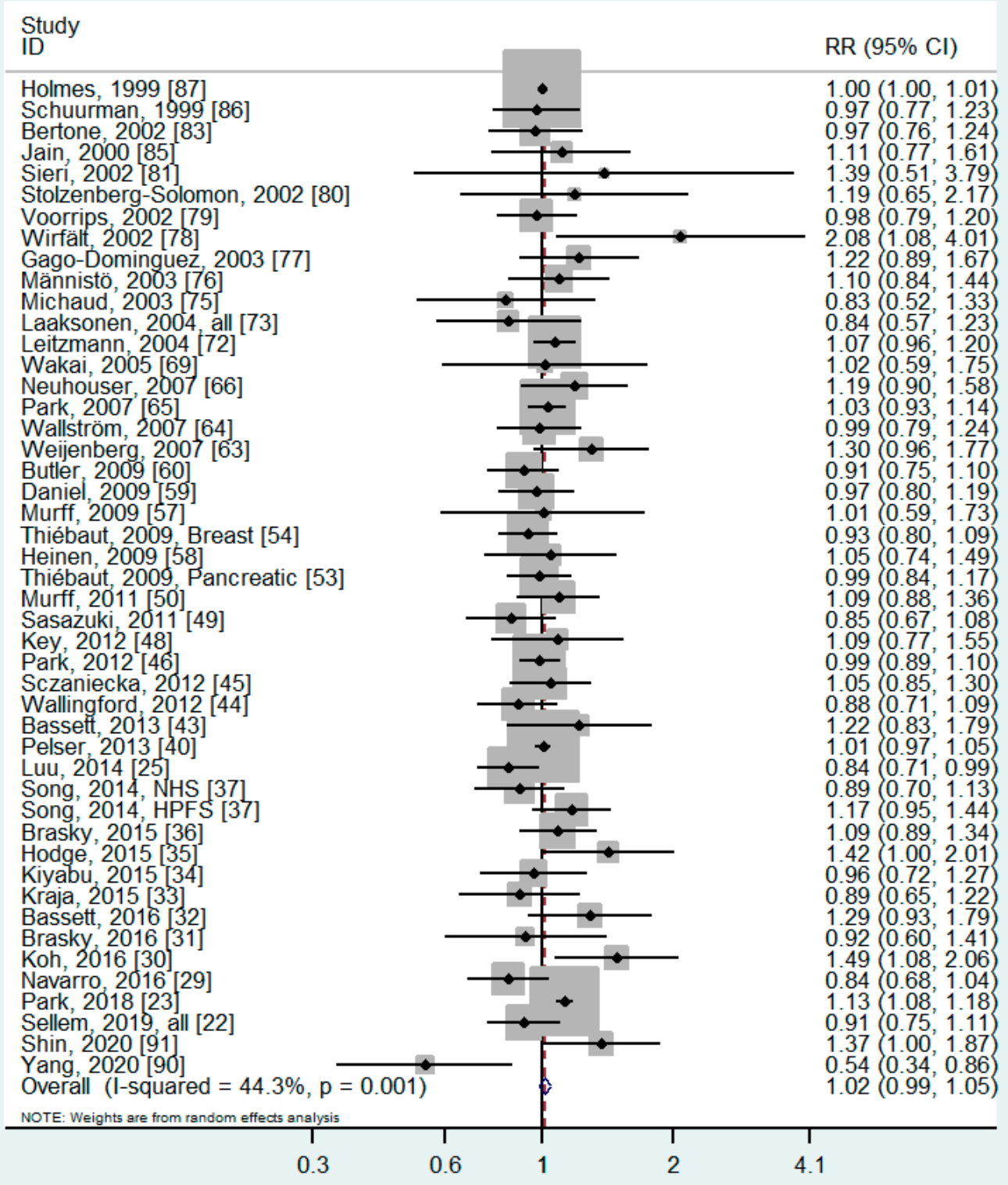

Relative Risk $(95 \% \mathrm{Cl})$

Figure 1. Forest plot of prospective studies of cancer for the highest versus lowest category of n-6 PUFA intake, using a random-effects model. 
Table 1. Summary of pooled relative risks (RR) of cancer risk for n-6 polyunsaturated fatty acid (PUFA) intake.

\begin{tabular}{|c|c|c|c|c|c|}
\hline \multirow{2}{*}{ Variable } & \multirow{2}{*}{ No. of Studies } & \multirow{2}{*}{$\mathbf{R R}$} & \multirow{2}{*}{$95 \%$ CI } & \multicolumn{2}{|c|}{ Heterogeneity } \\
\hline & & & & $I^{2}(\%)$ & $p$ \\
\hline \multicolumn{6}{|c|}{ Cancer site } \\
\hline Any & 47 & 1.02 & $0.99-1.05$ & 38.9 & 0.01 \\
\hline Breast & 13 & 1.00 & $1.00-1.01$ & 0.0 & 0.49 \\
\hline Colorectal & 11 & 0.99 & $0.90-1.09$ & 36.0 & 0.11 \\
\hline Prostate & 10 & 1.02 & $0.99-1.06$ & 0.0 & 0.68 \\
\hline Pancreatic & 4 & 0.99 & $0.86-1.14$ & 0.0 & 0.80 \\
\hline Gynecological & 4 & 1.04 & $0.90-1.19$ & 0.0 & 0.81 \\
\hline Skin & 3 & 1.02 & $0.80-1.29$ & 79.7 & 0.03 \\
\hline Others & 3 & 1.10 & $0.63-1.92$ & 89.6 & 0.002 \\
\hline \multicolumn{6}{|c|}{ Type of fatty acids } \\
\hline LA & 30 & 0.99 & $0.94-1.04$ & 23.2 & 0.13 \\
\hline AA & 22 & 1.02 & $0.98-1.06$ & 39.0 & 0.04 \\
\hline DGLA & 4 & 1.10 & $0.93-1.29$ & 0.0 & 0.93 \\
\hline GLA & 1 & 0.92 & $0.53-1.60$ & - & - \\
\hline \multicolumn{6}{|l|}{ Sex } \\
\hline Men & 17 & 1.03 & $0.98-1.08$ & 28.1 & 0.14 \\
\hline Women & 26 & 1.01 & $0.97-1.06$ & 35.0 & 0.04 \\
\hline
\end{tabular}

Abbreviations: LA, linoleic acid, AA, arachidonic acid; DGLA, dihomo- $\gamma$-linolenic acid; GLA, $\gamma$-linolenic acid.

\subsection{Blood Levels of n-6 PUFAs}

Twenty-nine articles including 13,966 cancer cases evaluated the association between blood levels of n-6 PUFAs and the risk of cancer $[24,26-28,32,35,38,39,41-43,47,51,52,55,56,61,62,67,68,70,71,73,74,76,82,84,88,89]$ (Supplementary Table S2). The pooled RR of any type of cancer for the highest versus lowest categories of blood n-6 PUFAs was 0.92 (95\% CI: 0.86-0.98) with no significant heterogeneity ( $p=0.26, I^{2}=13.8 \%$ ) (Figure 2). The results of the sensitivity analysis, which removed one study at a time, showed that the pooled RR ranged from 0.90 (95\% CI: $0.85-0.96)$ to 0.93 (95\% CI: 0.87-0.99). There was no evidence of publication bias (Begg's $P=0.18$; Egger's $P=0.22$ ). Subgroup analysis by cancer site showed a significant inverse association between blood levels of $n-6$ PUFAs and breast cancer (RR $=0.87 ; 95 \% \mathrm{CI}$ : 0.77-0.98), and nonsignificant inverse associations were observed between blood levels of n-6 PUFAs and prostate $(\mathrm{RR}=0.94 ; 95 \% \mathrm{CI}: 0.84-1.05)$, colorectal ( $\mathrm{RR}=0.92 ; 95 \% \mathrm{CI}: 0.77-1.10)$, and other cancers $(R R=0.90 ; 95 \%$ CI: 0.75-1.08) (Table 2). For the type of n-6 PUFAs, the blood levels of LA showed an inverse association with the risk of cancer ( $R R=0.91 ; 95 \%$ CI: $0.82-1.00)$, but other types of $n-6$ PUFAs indicated nonsignificant inverse associations. When analyzed by sex, a slightly stronger inverse association was observed in women $(R R=0.88 ; 95 \%$ CI: $0.79-0.97)$ than in men $(R R=0.92 ; 95 \%$ CI: $0.83-1.02)$.

The results of dose-response analysis showed an inverse linear association between blood levels of n-6 PUFAs and the risk of cancer. A 5\% increase in blood levels of n-6 PUFAs was associated with a $2 \%$ lower risk of cancer ( $R R=0.98 ; 95 \%$ CI: 0.97-0.99) (Figure 3A). There was no evidence of a nonlinear association $(p=0.43)$. By type of $\mathrm{n}-6$ PUFAs, blood levels of LA were also inversely associated with risk of cancer (RR for $5 \%$ increase in LA $=0.97$; $95 \%$ CI: 0.95-0.99) without significant evidence of nonlinearity ( $p=0.30$ ) (Figure 3B). For blood levels of AA, dihomo- $\gamma$-linolenic acid (DGLA), and $\gamma$-linolenic acid (GLA), no significant associations were observed. 
Study

ID

\section{Harvei, 1997 [89]}

Chajés, 1999 [88]

Pala, 2001 [84]

Saadatian-Elahi, 2002 [82]

Rissanen, 2003 [74]

Männistö, 2003 [76]

Laaksonen, 2004, all [73]

Wirfält, 2004 [71]

Kojima, 2005 [70]

Hall, 2007 [67]

Chavarro, 2007 [68]

Chajés, 2008 [62]

Crowe, 2008 [61]

Park, 2009 [56]

Takata, 2009 [55]

Brasky, 2011 [52]

Chajés, 2011 [51]

Morimoto, 2012 [47]

Bassett, 2013 [43]

Brasky, 2013 [42]

Cheng, 2013 [41]

Wallingford, 2013 [39]

Pouchieu, 2014, all [38]

Hodge, 2015 [35]

Bassett, 2016 [32]

Butler, 2017 [28]

Chajés, 2017 [27]

Hirko, 2018 [26]

Matejcic, 2018 [24]

Overall (l-squared $=13.8 \%, p=0.256$ )

NOTE: Weights are from random effects analysis

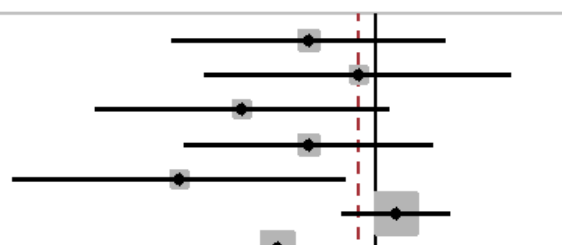

$\operatorname{RR}(95 \% \mathrm{Cl})$

$0.70(0.34,1.46)$

$0.91(0.40,2.07)$

$0.49(0.22,1.08)$

$0.70(0.36,1.36)$

$0.35(0.14,0.86)$

$1.12(0.84,1.50)$

$0.59(0.39,0.90)$

$0.97(0.79,1.17)$

$0.88(0.48,1.61)$

$0.63(0.34,1.17)$

$1.11(0.91,1.37)$

$0.97(0.61,1.54)$

$0.90(0.75,1.08)$

$0.76(0.50,1.16)$

$1.14(0.61,2.13)$

$0.95(0.79,1.14)$

$1.15(0.67,1.97)$

$1.12(0.73,1.72)$

$0.76(0.53,1.09)$

$0.90(0.74,1.09)$

$1.09(0.85,1.39)$

$0.81(0.63,1.04)$

$1.46(0.85,2.51)$

$1.06(0.75,1.49)$

$0.82(0.59,1.14)$

$0.92(0.72,1.17)$

$0.81(0.69,0.96)$

$0.98(0.69,1.40)$

$0.87(0.58,1.30)$

$0.92(0.86,0.98)$

\section{Relative Risk $(95 \% \mathrm{Cl})$}

Figure 2. Forest plot of prospective studies of cancer for the highest versus lowest category of blood levels of n-6 PUFAs, using a random-effects model.
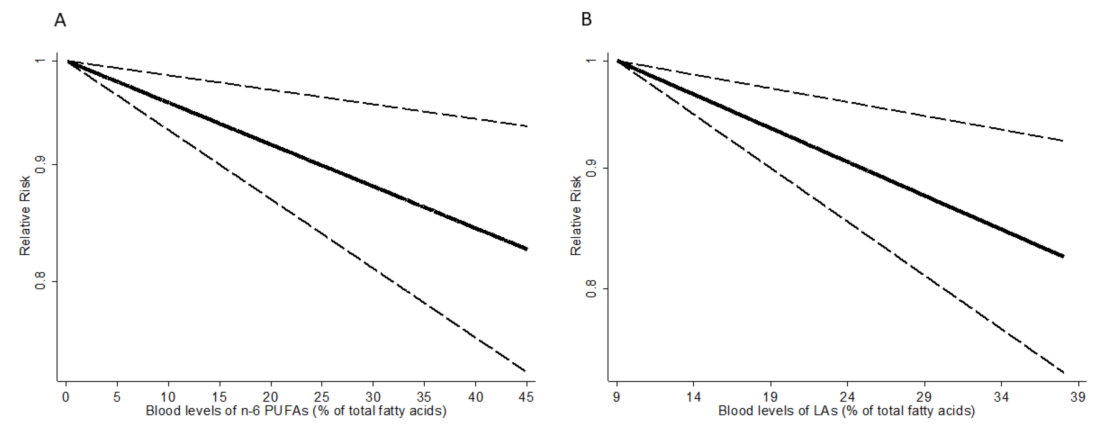

Figure 3. Dose-response association between blood levels of n-6 PUFAs (A), LA (B) and relative risk of cancer. The vertical axis is on a log scale. 
Table 2. Summary of pooled relative risks (RR) of cancer risk for blood levels of n-6 PUFAs.

\begin{tabular}{cccccc}
\hline Variable & No. of Studies & RR & $\mathbf{9 5 \%} \mathbf{C I}$ & \multicolumn{2}{c}{ Heterogeneity } \\
\cline { 5 - 6 } & & & & $\mathbf{I}^{\mathbf{2}} \mathbf{( \% )}$ & $\boldsymbol{p}$ \\
\hline Cancer site & & & & & \\
Any & 29 & 0.92 & $0.86-0.98$ & 13.8 & 0.26 \\
Breast & 11 & 0.87 & $0.77-0.98$ & 10.2 & 0.35 \\
Prostate & 10 & 0.94 & $0.84-1.05$ & 39.3 & 0.10 \\
Colorectal & 4 & 0.92 & $0.77-1.10$ & 0.0 & 0.55 \\
Others & 4 & 0.90 & $0.75-1.08$ & 0.0 & 0.47 \\
Type of fatty acids & & & & & \\
LA & 28 & 0.91 & $0.82-1.00$ & 42.2 & 0.01 \\
AA & 17 & 0.98 & $0.91-1.05$ & 0.0 & 0.66 \\
DGLA & 26 & 0.99 & $0.88-1.12$ & 30.5 & 0.11 \\
GLA & 17 & 0.94 & $0.83-1.06$ & 23.4 & 0.19 \\
Sex & & & & & \\
Men & 13 & 0.92 & $0.83-1.02$ & 30.1 & 0.14 \\
Women & 13 & 0.88 & $0.79-0.97$ & 0.0 & 0.48
\end{tabular}

Abbreviations: PUFA, polyunsaturated fatty acid; LA, linoleic acid, AA, arachidonic acid; DGLA, dihomo- $\gamma$-linolenic acid; GLA, $\gamma$-linolenic acid.

\section{Discussion}

In the present study, we conducted a meta-analysis of prospective studies on the association between intake or blood levels of n-6 PUFAs and the risk of cancer. Our findings indicate that high blood n-6 PUFA levels are associated with a lower risk of cancer. Compared to people with the lowest blood levels of n-6 PUFAs, those with the highest blood levels of n-6 PUFAs had an 8\% lower risk of cancer from any site. In the dose-response analysis, a $2 \%$ decreased risk of cancer was observed for a 5\% increase in blood levels of n-6 PUFAs. When considering the site of cancer, breast cancer risk showed the strongest inverse association with blood levels of n-6 PUFAs. By type of n-6 PUFAs, the strongest inverse association was observed between blood levels of LA and risk of cancer. For sex, the inverse association was slightly stronger in women than in men. Regarding n-6 PUFA intake, no significant association was found in relation to the risk of cancer.

A previous meta-analysis published in 1998 summarized the results from studies on LA intake and breast, colorectal, and prostate cancer [6]. This study observed no significant association and concluded that high intake of LA did not substantially increase the risk of breast, colorectal, or prostate cancer in humans. Another meta-analysis investigating the association of intake and serum levels of LA with the risk of breast cancer suggested that LA may be associated with a decreased risk of breast cancer, reporting a nonsignificant inverse association [92]. We also found a null association between n-6 PUFA intake and the risk of cancer in the current meta-analysis.

Most studies included in our meta-analysis of n-6 PUFA intake assessed dietary intake using food frequency questionnaires. The few studies using a food diary, food record, or 24-h dietary recall showed a nonsignificant inverse [22] or positive [48,73] association between n-6 PUFA intake and the risk of cancer. Several previous studies investigating the association between fat intake and risk of cancer reported differences in results by dietary assessment methods. They found a significant association between fat intake and breast cancer risk when using food diaries or records, but a null association was observed when using food frequency questionnaires [8,93]. Dietary measurement error, which often occurs with food frequency questionnaires, might affect the results. Furthermore, fatty acids are particularly vulnerable to measurement errors because types of fat vary tremendously and assorted foods have different compositions of fatty acids [94]. Our results indicating a null association between n-6 PUFA intake and the risk of cancer may also have been affected by measurement errors. Because of the difficulties in estimating fat intake with dietary assessment, the use of circulating fatty acids can be an alternative approach for evaluating the association between fatty acids and the risk of disease. Although blood concentrations reflect absorption and metabolism as well as intake, PUFAs in blood 
may reflect intake relatively well because PUFAs were nearly derived from exogenous sources [32]. We found a significant inverse association between blood levels of n-6 PUFAs and risk of cancer, but a relatively small number of studies were included, compared with those assessing n-6 PUFA intake. Future studies on n-6 PUFAs and risk of cancer should consider blood levels of n-6 PUFAs as well as n-6 PUFA intake as an exposure.

The results from the subgroup analysis by cancer site showed that the inverse association between blood levels of n-6 PUFAs and the risk of breast cancer was stronger than that of other sites. Breast cancer is a common cancer that has been studied a lot in relation to fat intake, and thus the largest number of studies were included in our meta-analysis. A large prospective study involving 2982 breast cancer cases found a 19\% lower risk of breast cancer in women with the highest blood levels of total n-6 PUFAs, compared to those with the lowest blood levels of total n-6 PUFAs [27]. When we analyzed by the type of n-6 PUFAs, LA showed a stronger inverse association with the risk of cancer than the other types of n-6 PUFAs. The differences in the risk of disease by type of n-6 PUFAs were also shown in previous studies. A cohort study including 2792 older adults found that high circulating LA was related to lower total and coronary heart disease (CHD) mortality, but no significant association was observed for other types of n-6 PUFAs [95]. LA accounts for the largest part of dietary intake or blood levels of n-6 PUFAs, and other n-6 PUFAs are produced from LA via desaturase and elongase [1]. In the subgroup analysis by sex, we found a stronger inverse association in women than in men, but this difference seems to be due to discrepancies in cancer sites because all breast cancer results were included in the subgroup analysis of women.

Although the evidence for the association between n-6 PUFAs and risk of disease was relatively limited compared to that of n-3 PUFAs, one meta-analysis including 310,602 individuals reported a low risk of CHD among people with high intake of LA [96]. Another meta-analysis including 22 observational studies found that LA biomarkers (blood/tissue) were inversely associated with the risk of nonfatal CHD [97]. Increasing numbers of studies have also suggested that n-6 PUFAs may be involved in anticancer processes [1]. Previous experimental studies observed that LA inhibited the proliferation and growth of colon cancer cells by enhancing cellular oxidant status and inducing mitochondrial dysfunction [98-100]. GLA was also observed to induce cancer cell apoptosis by altering mitochondrial metabolism and decreasing hexokinase and carnitine palmitoyltransferase I activities [101,102]. In addition, studies on cancer cells found that DGLA free radical derivatives from cyclooxygenase-catalyzed lipid peroxidation can inhibit cell growth and induce cell cycle arrest and apoptosis in human colon cancer cells [103]. Diets rich in n-6 PUFAs have been known to raise the risk of cancer, and it has been turned out to be mostly due to AA, which can produce eicosanoids with inflammatory properties [104]. Prostaglandin $\mathrm{E}_{2}\left(\mathrm{PGE}_{2}\right)$, which is derived from $\mathrm{AA}$, has been found to increase tumor growth in previous studies [7]. Concerns about diets high in n-6 PUFAs were based on the hypothesis that LA, which takes up the largest portion of n-6 PUFA intake, is converted to AA [105]. However, the production of AA from LA is tightly regulated [106], and the extent of the conversion of LA to AA was observed to be as low as approximately $0.2 \%$ in tracer studies [107].

To the best of our knowledge, this is the first meta-analysis investigating the association between intakes or blood levels of n-6 PUFAs and risk of cancer from any site. As few studies have focused on n-6 PUFAs among the studies examining the association between fatty acids and the risk of cancer, our meta-analysis may provide useful information for future studies investigating the effect of n-6 PUFAs on the development of cancer. We tried to avoid recall bias by including only prospective studies in the meta-analysis. The inverse association between blood levels of n-6 PUFAs and risk of cancer was observed both in categorical (highest versus lowest) and dose-response meta-analyses. There was no significant heterogeneity, and the robustness of the results was identified through sensitivity analysis. In addition, there was no publication bias, which often could be of concern in meta-analysis. Despite these strengths, several limitations of this study should be noted. First, our meta-analysis of the association between n-6 PUFAs and the risk of cancer did not completely cover all cancer sites since previous studies have mostly focused on the risk of common cancers, such as breast, colorectal, 
or prostate cancer. Second, meta-analysis cannot solve problems of confounding that were inherent in the original studies. Although all studies included in the meta-analysis adjusted for age and most of the studies additionally controlled for major confounders such as BMI, smoking or alcohol, unknown or unmeasured factors might be a cause of confounding. Third, blood levels of n-6 PUFAs were measured at only at baseline, and thus, there is some possibility of change in blood levels of n- 6 PUFAs during follow-up times. However, a previous study showed that a single measurement of blood levels of fatty acids reasonably reflected the blood levels over long periods [108].

\section{Conclusions}

In conclusion, the current meta-analysis indicated that individuals with high levels of n-6 PUFAs in blood (35.9\% of total fatty acids, median) had a lower risk of cancer, compared to those with low levels of n-6 PUFAs in blood (28.7\% of total fatty acids, median). The observed inverse association between blood levels of n-6 PUFAs and cancer risk was strong for breast cancer, LA, and women. We found no significant association between n-6 PUFA intake and the risk of cancer. Taken together our findings, n-6 PUFAs are unlikely to have an adverse effect on the development of cancer. Although it is not desirable to encourage people to eat high n-6 PUFAs, it might not be necessary to reduce n-6 PUFA intake excessively. Further well-designed prospective studies that use food records as a dietary assessment tool, consider blood levels of n-6 PUFAs as an exposure, or cover the risk of rare cancers are warranted to verify the effect of n-6 PUFAs on the risk of cancer.

Supplementary Materials: The following are available online at http://www.mdpi.com/2072-6643/12/9/2523/s1, Table S1: Characteristics of Prospective Studies Included in the Meta-Analysis of n-6 polyunsaturated fatty acid (PUFA) intake and colorectal cancer, Table S2: Characteristics of Prospective Studies Included in the Meta-Analysis of blood levels of n-6 polyunsaturated fatty acids (PUFAs) and colorectal cancer Figure S1: Flow chart of study selection

Author Contributions: Y.K. and J.K. conceptualization; Y.K. methodology; Y.K. statistical analysis; Y.K. and J.K. investigation; Y.K. and J.K. data curation; Y.K. writing-original draft preparation; Y.K. and J.K. writing-review and editing. All authors have read and agreed to the published version of the manuscript.

Funding: This research was funded by the National Cancer Center in Korea, grant number 1910330.

Acknowledgments: The authors would like to acknowledge the contribution of Julie K. Bassett and Theodore M. Brasky for providing additional information to be included in the dose-response analysis.

Conflicts of Interest: The authors declare no conflict of interest.

\section{References}

1. Xu, Y.; Qian, S.Y. Anti-cancer activities of omega-6 polyunsaturated fatty acids. Biomed. J. 2014, 37, 112-119. [PubMed]

2. Marion-Letellier, R.; Savoye, G.; Ghosh, S. Polyunsaturated fatty acids and inflammation. IUBMB Life 2015, 67, 659-667. [CrossRef] [PubMed]

3. Marventano, S.; Kolacz, P.; Castellano, S.; Galvano, F.; Buscemi, S.; Mistretta, A.; Grosso, G. A review of recent evidence in human studies of n-3 and n-6 pufa intake on cardiovascular disease, cancer, and depressive disorders: Does the ratio really matter? Int. J. Food Sci. Nutr. 2015, 66, 611-622. [CrossRef] [PubMed]

4. Blasbalg, T.L.; Hibbeln, J.R.; Ramsden, C.E.; Majchrzak, S.F.; Rawlings, R.R. Changes in consumption of omega-3 and omega-6 fatty acids in the united states during the 20th century. Am. J. Clin. Nutr. 2011, 93, 950-962. [CrossRef]

5. Simopoulos, A.P. Importance of the omega-6/omega-3 balance in health and disease: Evolutionary aspects of diet. World Rev. Nutr. Diet. 2011, 102, 10-21. [PubMed]

6. Zock, P.L.; Katan, M.B. Linoleic acid intake and cancer risk: A review and meta-analysis. Am. J. Clin. Nutr. 1998, 68, 142-153. [CrossRef]

7. Sakai, M.; Kakutani, S.; Horikawa, C.; Tokuda, H.; Kawashima, H.; Shibata, H.; Okubo, H.; Sasaki, S. Arachidonic acid and cancer risk: A systematic review of observational studies. BMC Cancer 2012, 12, 606. [CrossRef] 
8. Bingham, S.A.; Luben, R.; Welch, A.; Wareham, N.; Khaw, K.T.; Day, N. Are imprecise methods obscuring a relation between fat and breast cancer? Lancet 2003, 362, 212-214. [CrossRef]

9. Goris, A.H.; Westerterp-Plantenga, M.S.; Westerterp, K.R. Undereating and underrecording of habitual food intake in obese men: Selective underreporting of fat intake. Am. J. Clin. Nutr. 2000, 71, 130-134. [CrossRef]

10. Baylin, A.; Campos, H. The use of fatty acid biomarkers to reflect dietary intake. Curr. Opin. Lipidol. 2006, 17, 22-27. [CrossRef]

11. Moher, D.; Liberati, A.; Tetzlaff, J.; Altman, D.G.; Group, P. Preferred reporting items for systematic reviews and meta-analyses: The Prisma statement. PLoS Med. 2009, 6, e1000097. [CrossRef] [PubMed]

12. Wells, G.A.; Shea, B.; O'Connell, D.; Peterson, J.; Welch, V.; Losos, M.; Tugwell, P. The Newcastle-Ottawa Scale (nos) for Assessing the Quality of Nonrandomized Studies in Meta-Analysis. Available online: Http://www.Ohri.Ca/programs/clinical_epidemiology/oxford.Asp (accessed on 19 August 2020).

13. DerSimonian, R.; Laird, N. Meta-analysis in clinical trials. Control. Clin. Trials 1986, 7, 177-188. [CrossRef]

14. Greenland, S.; Longnecker, M.P. Methods for trend estimation from summarized dose-response data, with applications to meta-analysis. Am. J. Epidemiol. 1992, 135, 1301-1309. [CrossRef]

15. Berlin, J.A.; Longnecker, M.P.; Greenland, S. Meta-analysis of epidemiologic dose-response data. Epidemiology 1993, 4, 218-228. [CrossRef]

16. Orsini, N.; Bellocco, R.; Greenland, S. Generalized least squares for trend estimation of summarized dose-response data. Stata J. 2006, 6, 40-57. [CrossRef]

17. Orsini, N.; Li, R.; Wolk, A.; Khudyakov, P.; Spiegelman, D. Meta-analysis for linear and nonlinear doseresponse relations: Examples, an evaluation of approximations, and software. Am. J. Epidemiol. 2012, 175, 66-73. [CrossRef]

18. Cochran, W.G. The combination of estimates from different experiments. Biometrics 1954, 10, 101-129. [CrossRef]

19. Higgins, J.P.; Thompson, S.G.; Deeks, J.J.; Altman, D.G. Measuring inconsistency in meta-analyses. BMJ 2003, 327, 557-560. [CrossRef]

20. Begg, C.B.; Mazumdar, M. Operating characteristics of a rank correlation test for publication bias. Biometrics 1994, 50, 1088-1101. [CrossRef]

21. Egger, M.; Davey Smith, G.; Schneider, M.; Minder, C. Bias in meta-analysis detected by a simple, graphical test. BMJ 1997, 315, 629-634. [CrossRef]

22. Sellem, L.; Srour, B.; Guéraud, F.; Pierre, F.; Kesse-Guyot, E.; Fiolet, T.; Lavalette, C.; Egnell, M.; Latino-Martel, P.; Fassier, P.; et al. Saturated, mono- and polyunsaturated fatty acid intake and cancer risk: Results from the French prospective cohort nutrinet-santé. Eur. J. Nutr. 2019, 58, 1515-1527. [CrossRef]

23. Park, M.K.; Li, W.Q.; Qureshi, A.A.; Cho, E. Fat intake and risk of skin cancer in U.S. Adults. Cancer Epidemiol. Biomark. Prev. 2018, 27, 776-782. [CrossRef]

24. Matejcic, M.; Lesueur, F.; Biessy, C.; Renault, A.L.; Mebirouk, N.; Yammine, S.; Keski-Rahkonen, P.; Li, K.; Hemon, B.; Weiderpass, E.; et al. Circulating plasma phospholipid fatty acids and risk of pancreatic cancer in a large european cohort. Int. J. Cancer 2018, 143, 2437-2448. [CrossRef]

25. Luu, H.N.; Cai, H.; Murff, H.J.; Xiang, Y.B.; Cai, Q.; Li, H.; Gao, J.; Yang, G.; Lan, Q.; Gao, Y.T.; et al. A prospective study of dietary polyunsaturated fatty acids intake and lung cancer risk. Int. J. Cancer 2018, 143, 2225-2237. [CrossRef]

26. Hirko, K.A.; Chai, B.; Spiegelman, D.; Campos, H.; Farvid, M.S.; Hankinson, S.E.; Willett, W.C.; Eliassen, A.H. Erythrocyte membrane fatty acids and breast cancer risk: A prospective analysis in the nurses' health study ii. Int. J. Cancer 2018, 142, 1116-1129. [CrossRef]

27. Chajes, V.; Assi, N.; Biessy, C.; Ferrari, P.; Rinaldi, S.; Slimani, N.; Lenoir, G.M.; Baglietto, L.; His, M.; Boutron-Ruault, M.C.; et al. A prospective evaluation of plasma phospholipid fatty acids and breast cancer risk in the epic study. Ann. Oncol. 2017, 28, 2836-2842. [CrossRef]

28. Butler, L.M.; Yuan, J.M.; Huang, J.Y.; Su, J.; Wang, R.; Koh, W.P.; Ong, C.N. Plasma fatty acids and risk of colon and rectal cancers in the Singapore Chinese health study. NPJ Precis. Oncol. 2017, 1, 38. [CrossRef]

29. Navarro, S.L.; Neuhouser, M.L.; Cheng, T.D.; Tinker, L.F.; Shikany, J.M.; Snetselaar, L.; Martinez, J.A.; Kato, I.; Beresford, S.A.; Chapkin, R.S.; et al. The interaction between dietary fiber and fat and risk of colorectal cancer in the women's health initiative. Nutrients 2016, 8, 779. [CrossRef]

30. Koh, W.P.; Dan, Y.Y.; Goh, G.B.; Jin, A.; Wang, R.; Yuan, J.M. Dietary fatty acids and risk of hepatocellular carcinoma in the Singapore Chinese health study. Liver Int. 2016, 36, 893-901. [CrossRef] 
31. Brasky, T.M.; Sponholtz, T.R.; Palmer, J.R.; Rosenberg, L.; Ruiz-Narvaez, E.A.; Wise, L.A. Associations of dietary long-chain omega-3 polyunsaturated fatty acids and fish consumption with endometrial cancer risk in the black women's health study. Am. J. Epidemiol. 2016, 183, 199-209. [CrossRef]

32. Bassett, J.K.; Hodge, A.M.; English, D.R.; MacInnis, R.J.; Giles, G.G. Plasma phospholipids fatty acids, dietary fatty acids, and breast cancer risk. Cancer Causes Control 2016, 27, 759-773. [CrossRef]

33. Kraja, B.; Muka, T.; Ruiter, R.; de Keyser, C.E.; Hofman, A.; Franco, O.H.; Stricker, B.H.; Kiefte-de Jong, J.C. Dietary fiber intake modifies the positive association between n-3 pufa intake and colorectal cancer risk in a Caucasian population. J. Nutr. 2015, 145, 1709-1716. [CrossRef] [PubMed]

34. Kiyabu, G.Y.; Inoue, M.; Saito, E.; Abe, S.K.; Sawada, N.; Ishihara, J.; Iwasaki, M.; Yamaji, T.; Shimazu, T.; Sasazuki, S.; et al. Fish, n-3 polyunsaturated fatty acids and n-6 polyunsaturated fatty acids intake and breast cancer risk: The japan public health center-based prospective study. Int. J. Cancer 2015, 137, 2915-2926. [CrossRef] [PubMed]

35. Hodge, A.M.; Williamson, E.J.; Bassett, J.K.; MacInnis, R.J.; Giles, G.G.; English, D.R. Dietary and biomarker estimates of fatty acids and risk of colorectal cancer. Int. J. Cancer 2015, 137, 1224-1234. [CrossRef] [PubMed]

36. Brasky, T.M.; Rodabough, R.J.; Liu, J.; Kurta, M.L.; Wise, L.A.; Orchard, T.S.; Cohn, D.E.; Belury, M.A.; White, E.; Manson, J.E.; et al. Long-chain omega-3 fatty acid intake and endometrial cancer risk in the women's health initiative. Am. J. Clin. Nutr. 2015, 101, 824-834. [CrossRef]

37. Song, M.; Chan, A.T.; Fuchs, C.S.; Ogino, S.; Hu, F.B.; Mozaffarian, D.; Ma, J.; Willett, W.C.; Giovannucci, E.L.; $\mathrm{Wu}, \mathrm{K}$. Dietary intake of fish, omega-3 and omega- 6 fatty acids and risk of colorectal cancer: A prospective study in u.S. Men and women. Int. J. Cancer 2014, 135, 2413-2423. [CrossRef]

38. Pouchieu, C.; Chajes, V.; Laporte, F.; Kesse-Guyot, E.; Galan, P.; Hercberg, S.; Latino-Martel, P.; Touvier, M. Prospective associations between plasma saturated, monounsaturated and polyunsaturated fatty acids and overall and breast cancer risk-modulation by antioxidants: A nested case-control study. PLoS ONE 2014, 9, e90442. [CrossRef]

39. Wallingford, S.C.; Hughes, M.C.; Green, A.C.; van der Pols, J.C. Plasma omega-3 and omega-6 concentrations and risk of cutaneous basal and squamous cell carcinomas in Australian adults. Cancer Epidemiol. Biomark. Prev. 2013, 22, 1900-1905. [CrossRef]

40. Pelser, C.; Mondul, A.M.; Hollenbeck, A.R.; Park, Y. Dietary fat, fatty acids, and risk of prostate cancer in the nih-aarp diet and health study. Cancer Epidemiol. Biomark. Prev. 2013, 22, 697-707. [CrossRef]

41. Cheng, T.Y.; King, I.B.; Barnett, M.J.; Ambrosone, C.B.; Thornquist, M.D.; Goodman, G.E.; Neuhouser, M.L. Serum phospholipid fatty acids, genetic variation in myeloperoxidase, and prostate cancer risk in heavy smokers: A gene-nutrient interaction in the carotene and retinol efficacy trial. Am. J. Epidemiol. 2013, 177, 1106-1117. [CrossRef]

42. Brasky, T.M.; Darke, A.K.; Song, X.; Tangen, C.M.; Goodman, P.J.; Thompson, I.M.; Meyskens, F.L., Jr.; Goodman, G.E.; Minasian, L.M.; Parnes, H.L.; et al. Plasma phospholipid fatty acids and prostate cancer risk in the select trial. J. Natl. Cancer Inst. 2013, 105, 1132-1141. [CrossRef] [PubMed]

43. Bassett, J.K.; Severi, G.; Hodge, A.M.; MacInnis, R.J.; Gibson, R.A.; Hopper, J.L.; English, D.R.; Giles, G.G. Plasma phospholipid fatty acids, dietary fatty acids and prostate cancer risk. Int. J. Cancer 2013, 133, 1882-1891. [CrossRef] [PubMed]

44. Wallingford, S.C.; van As, J.A.; Hughes, M.C.; Ibiebele, T.I.; Green, A.C.; van der Pols, J.C. Intake of omega- 3 and omega- 6 fatty acids and risk of basal and squamous cell carcinomas of the skin: A longitudinal community-based study in Australian adults. Nutr. Cancer 2012, 64, 982-990. [CrossRef] [PubMed]

45. Sczaniecka, A.K.; Brasky, T.M.; Lampe, J.W.; Patterson, R.E.; White, E. Dietary intake of specific fatty acids and breast cancer risk among postmenopausal women in the vital cohort. Nutr. Cancer 2012, 64, 1131-1142. [CrossRef]

46. Park, S.Y.; Kolonel, L.N.; Henderson, B.E.; Wilkens, L.R. Dietary fat and breast cancer in postmenopausal women according to ethnicity and hormone receptor status: The multiethnic cohort study. Cancer Prev. Res. 2012, 5, 216-228. [CrossRef]

47. Morimoto, Y.; Conroy, S.M.; Ollberding, N.J.; Henning, S.M.; Franke, A.A.; Wilkens, L.R.; Goodman, M.T.; Hernandez, B.Y.; Le Marchand, L.; Henderson, B.E.; et al. Erythrocyte membrane fatty acid composition, serum lipids, and non-Hodgkin's lymphoma risk in a nested case-control study: The multiethnic cohort. Cancer Causes Control 2012, 23, 1693-1703. [CrossRef] 
48. Key, T.J.; Appleby, P.N.; Masset, G.; Brunner, E.J.; Cade, J.E.; Greenwood, D.C.; Stephen, A.M.; Kuh, D.; Bhaniani, A.; Powell, N.; et al. Vitamins, minerals, essential fatty acids and colorectal cancer risk in the united kingdom dietary cohort consortium. Int. J. Cancer 2012, 131, E320-E325. [CrossRef]

49. Sasazuki, S.; Inoue, M.; Iwasaki, M.; Sawada, N.; Shimazu, T.; Yamaji, T.; Takachi, R.; Tsugane, S. Intake of n-3 and n-6 polyunsaturated fatty acids and development of colorectal cancer by subsite: Japan public health center-based prospective study. Int. J. Cancer 2011, 129, 1718-1729. [CrossRef]

50. Murff, H.J.; Shu, X.O.; Li, H.; Yang, G.; Wu, X.; Cai, H.; Wen, W.; Gao, Y.T.; Zheng, W. Dietary polyunsaturated fatty acids and breast cancer risk in chinese women: A prospective cohort study. Int. J. Cancer 2011, 128, 1434-1441. [CrossRef]

51. Chajes, V.; Jenab, M.; Romieu, I.; Ferrari, P.; Dahm, C.C.; Overvad, K.; Egeberg, R.; Tjonneland, A.; Clavel-Chapelon, F.; Boutron-Ruault, M.C.; et al. Plasma phospholipid fatty acid concentrations and risk of gastric adenocarcinomas in the European prospective investigation into cancer and nutrition (epic-eurgast). Am. J. Clin. Nutr. 2011, 94, 1304-1313. [CrossRef]

52. Brasky, T.M.; Till, C.; White, E.; Neuhouser, M.L.; Song, X.; Goodman, P.; Thompson, I.M.; King, I.B.; Albanes, D.; Kristal, A.R. Serum phospholipid fatty acids and prostate cancer risk: Results from the prostate cancer prevention trial. Am. J. Epidemiol. 2011, 173, 1429-1439. [CrossRef] [PubMed]

53. Thiebaut, A.C.; Jiao, L.; Silverman, D.T.; Cross, A.J.; Thompson, F.E.; Subar, A.F.; Hollenbeck, A.R.; Schatzkin, A.; Stolzenberg-Solomon, R.Z. Dietary fatty acids and pancreatic cancer in the nih-aarp diet and health study. J. Natl. Cancer Inst. 2009, 101, 1001-1011. [CrossRef] [PubMed]

54. Thiebaut, A.C.; Chajes, V.; Gerber, M.; Boutron-Ruault, M.C.; Joulin, V.; Lenoir, G.; Berrino, F.; Riboli, E.; Benichou, J.; Clavel-Chapelon, F. Dietary intakes of omega- 6 and omega-3 polyunsaturated fatty acids and the risk of breast cancer. Int. J. Cancer 2009, 124, 924-931. [CrossRef] [PubMed]

55. Takata, Y.; King, I.B.; Neuhouser, M.L.; Schaffer, S.; Barnett, M.; Thornquist, M.; Peters, U.; Goodman, G.E. Association of serum phospholipid fatty acids with breast cancer risk among postmenopausal cigarette smokers. Cancer Causes Control 2009, 20, 497-504. [CrossRef] [PubMed]

56. Park, S.Y.; Wilkens, L.R.; Henning, S.M.; Le Marchand, L.; Gao, K.; Goodman, M.T.; Murphy, S.P.; Henderson, B.E.; Kolonel, L.N. Circulating fatty acids and prostate cancer risk in a nested case-control study: The multiethnic cohort. Cancer Causes Control 2009, 20, 211-223. [CrossRef]

57. Murff, H.J.; Shu, X.O.; Li, H.; Dai, Q.; Kallianpur, A.; Yang, G.; Cai, H.; Wen, W.; Gao, Y.T.; Zheng, W. A prospective study of dietary polyunsaturated fatty acids and colorectal cancer risk in Chinese women. Cancer Epidemiol. Biomark. Prev. 2009, 18, 2283-2291. [CrossRef]

58. Heinen, M.M.; Verhage, B.A.; Goldbohm, R.A.; van den Brandt, P.A. Meat and fat intake and pancreatic cancer risk in The Netherlands cohort study. Int. J. Cancer 2009, 125, 1118-1126. [CrossRef]

59. Daniel, C.R.; McCullough, M.L.; Patel, R.C.; Jacobs, E.J.; Flanders, W.D.; Thun, M.J.; Calle, E.E. Dietary intake of omega- 6 and omega-3 fatty acids and risk of colorectal cancer in a prospective cohort of U.S. Men and women. Cancer Epidemiol. Biomark. Prev. 2009, 18, 516-525. [CrossRef]

60. Butler, L.M.; Wang, R.; Koh, W.P.; Stern, M.C.; Yuan, J.M.; Yu, M.C. Marine n-3 and saturated fatty acids in relation to risk of colorectal cancer in Singapore Chinese: A prospective study. Int. J. Cancer 2009, 124, 678-686. [CrossRef]

61. Crowe, F.L.; Allen, N.E.; Appleby, P.N.; Overvad, K.; Aardestrup, I.V.; Johnsen, N.F.; Tjonneland, A.; Linseisen, J.; Kaaks, R.; Boeing, H.; et al. Fatty acid composition of plasma phospholipids and risk of prostate cancer in a case-control analysis nested within the european prospective investigation into cancer and nutrition. Am. J. Clin. Nutr. 2008, 88, 1353-1363.

62. Chajes, V.; Thiebaut, A.C.; Rotival, M.; Gauthier, E.; Maillard, V.; Boutron-Ruault, M.C.; Joulin, V.; Lenoir, G.M.; Clavel-Chapelon, F. Association between serum trans-monounsaturated fatty acids and breast cancer risk in the e3n-epic study. Am. J. Epidemiol. 2008, 167, 1312-1320. [CrossRef] [PubMed]

63. Weijenberg, M.P.; Luchtenborg, M.; de Goeij, A.F.; Brink, M.; van Muijen, G.N.; de Bruine, A.P.; Goldbohm, R.A.; van den Brandt, P.A. Dietary fat and risk of colon and rectal cancer with aberrant mlh1 expression, apc or kras genes. Cancer Causes Control 2007, 18, 865-879. [CrossRef] [PubMed]

64. Wallstrom, P.; Bjartell, A.; Gullberg, B.; Olsson, H.; Wirfalt, E. A prospective study on dietary fat and incidence of prostate cancer (Malmo, Sweden). Cancer Causes Control 2007, 18, 1107-1121. [CrossRef] [PubMed]

65. Park, S.Y.; Murphy, S.P.; Wilkens, L.R.; Henderson, B.E.; Kolonel, L.N. Fat and meat intake and prostate cancer risk: The multiethnic cohort study. Int. J. Cancer 2007, 121, 1339-1345. [CrossRef] 
66. Neuhouser, M.L.; Barnett, M.J.; Kristal, A.R.; Ambrosone, C.B.; King, I.; Thornquist, M.; Goodman, G. (n-6) pufa increase and dairy foods decrease prostate cancer risk in heavy smokers. J. Nutr. 2007, 137, 1821-1827. [CrossRef]

67. Hall, M.N.; Campos, H.; Li, H.; Sesso, H.D.; Stampfer, M.J.; Willett, W.C.; Ma, J. Blood levels of long-chain polyunsaturated fatty acids, aspirin, and the risk of colorectal cancer. Cancer Epidemiol. Biomark. Prev. 2007, 16, 314-321. [CrossRef]

68. Chavarro, J.E.; Stampfer, M.J.; Li, H.; Campos, H.; Kurth, T.; Ma, J. A prospective study of polyunsaturated fatty acid levels in blood and prostate cancer risk. Cancer Epidemiol. Biomark. Prev. 2007, 16, 1364-1370. [CrossRef]

69. Wakai, K.; Tamakoshi, K.; Date, C.; Fukui, M.; Suzuki, S.; Lin, Y.; Niwa, Y.; Nishio, K.; Yatsuya, H.; Kondo, T.; et al. Dietary intakes of fat and fatty acids and risk of breast cancer: A prospective study in japan. Cancer Sci. 2005, 96, 590-599. [CrossRef]

70. Kojima, M.; Wakai, K.; Tokudome, S.; Suzuki, K.; Tamakoshi, K.; Watanabe, Y.; Kawado, M.; Hashimoto, S.; Hayakawa, N.; Ozasa, K.; et al. Serum levels of polyunsaturated fatty acids and risk of colorectal cancer: A prospective study. Am. J. Epidemiol. 2005, 161, 462-471. [CrossRef]

71. Wirfalt, E.; Vessby, B.; Mattisson, I.; Gullberg, B.; Olsson, H.; Berglund, G. No relations between breast cancer risk and fatty acids of erythrocyte membranes in postmenopausal women of the Malmo diet cancer cohort (Sweden). Eur. J. Clin. Nutr. 2004, 58,761-770. [CrossRef]

72. Leitzmann, M.F.; Stampfer, M.J.; Michaud, D.S.; Augustsson, K.; Colditz, G.C.; Willett, W.C.; Giovannucci, E.L. Dietary intake of n-3 and n-6 fatty acids and the risk of prostate cancer. Am. J. Clin. Nutr. 2004, 80, 204-216. [CrossRef] [PubMed]

73. Laaksonen, D.E.; Laukkanen, J.A.; Niskanen, L.; Nyyssonen, K.; Rissanen, T.H.; Voutilainen, S.; Pukkala, E.; Hakkarainen, A.; Salonen, J.T. Serum linoleic and total polyunsaturated fatty acids in relation to prostate and other cancers: A population-based cohort study. Int. J. Cancer 2004, 111, 444-450. [CrossRef] [PubMed]

74. Rissanen, H.; Knekt, P.; Jarvinen, R.; Salminen, I.; Hakulinen, T. Serum fatty acids and breast cancer incidence. Nutr. Cancer 2003, 45, 168-175. [CrossRef] [PubMed]

75. Michaud, D.S.; Giovannucci, E.; Willett, W.C.; Colditz, G.A.; Fuchs, C.S. Dietary meat, dairy products, fat, and cholesterol and pancreatic cancer risk in a prospective study. Am. J. Epidemiol. 2003, 157, 1115-1125. [CrossRef] [PubMed]

76. Mannisto, S.; Pietinen, P.; Virtanen, M.J.; Salminen, I.; Albanes, D.; Giovannucci, E.; Virtamo, J. Fatty acids and risk of prostate cancer in a nested case-control study in male smokers. Cancer Epidemiol. Biomark. Prev. 2003, 12, 1422-1428.

77. Gago-Dominguez, M.; Yuan, J.M.; Sun, C.L.; Lee, H.P.; Yu, M.C. Opposing effects of dietary n-3 and n-6 fatty acids on mammary carcinogenesis: The Singapore Chinese health study. Br. J. Cancer 2003, 89, 1686-1692. [CrossRef]

78. Wirfalt, E.; Mattisson, I.; Gullberg, B.; Johansson, U.; Olsson, H.; Berglund, G. Postmenopausal breast cancer is associated with high intakes of omega6 fatty acids (Sweden). Cancer Causes Control 2002, 13, 883-893. [CrossRef]

79. Voorrips, L.E.; Brants, H.A.; Kardinaal, A.F.; Hiddink, G.J.; van den Brandt, P.A.; Goldbohm, R.A. Intake of conjugated linoleic acid, fat, and other fatty acids in relation to postmenopausal breast cancer: The Netherlands cohort study on diet and cancer. Am. J. Clin. Nutr. 2002, 76, 873-882. [CrossRef]

80. Stolzenberg-Solomon, R.Z.; Pietinen, P.; Taylor, P.R.; Virtamo, J.; Albanes, D. Prospective study of diet and pancreatic cancer in male smokers. Am. J. Epidemiol. 2002, 155, 783-792. [CrossRef]

81. Sieri, S.; Krogh, V.; Muti, P.; Micheli, A.; Pala, V.; Crosignani, P.; Berrino, F. Fat and protein intake and subsequent breast cancer risk in postmenopausal women. Nutr. Cancer 2002, 42, 10-17. [CrossRef]

82. Saadatian-Elahi, M.; Toniolo, P.; Ferrari, P.; Goudable, J.; Akhmedkhanov, A.; Zeleniuch-Jacquotte, A.; Riboli, E. Serum fatty acids and risk of breast cancer in a nested case-control study of the New York university women's health study. Cancer Epidemiol. Biomark. Prev. 2002, 11, 1353-1360.

83. Bertone, E.R.; Rosner, B.A.; Hunter, D.J.; Stampfer, M.J.; Speizer, F.E.; Colditz, G.A.; Willett, W.C.; Hankinson, S.E. Dietary fat intake and ovarian cancer in a cohort of us women. Am. J. Epidemiol. 2002, 156, 22-31. [CrossRef] [PubMed] 
84. Pala, V.; Krogh, V.; Muti, P.; Chajes, V.; Riboli, E.; Micheli, A.; Saadatian, M.; Sieri, S.; Berrino, F. Erythrocyte membrane fatty acids and subsequent breast cancer: A prospective Italian study. J. Natl. Cancer Inst. 2001, 93, 1088-1095. [CrossRef] [PubMed]

85. Jain, M.G.; Rohan, T.E.; Howe, G.R.; Miller, A.B. A cohort study of nutritional factors and endometrial cancer. Eur. J. Epidemiol. 2000, 16, 899-905. [CrossRef]

86. Schuurman, A.G.; van den Brandt, P.A.; Dorant, E.; Brants, H.A.; Goldbohm, R.A. Association of energy and fat intake with prostate carcinoma risk: Results from The Netherlands cohort study. Cancer 1999, 86, 1019-1027. [CrossRef]

87. Holmes, M.D.; Hunter, D.J.; Colditz, G.A.; Stampfer, M.J.; Hankinson, S.E.; Speizer, F.E.; Rosner, B.; Willett, W.C. Association of dietary intake of fat and fatty acids with risk of breast cancer. J. Am. Med. Assoc. 1999, 281, 914-920. [CrossRef]

88. Chajes, V.; Hulten, K.; Van Kappel, A.L.; Winkvist, A.; Kaaks, R.; Hallmans, G.; Lenner, P.; Riboli, E. Fatty-acid composition in serum phospholipids and risk of breast cancer: An incident case-control study in Sweden. Int. J. Cancer 1999, 83, 585-590. [CrossRef]

89. Harvei, S.; Bjerve, K.S.; Tretli, S.; Jellum, E.; Robsahm, T.E.; Vatten, L. Prediagnostic level of fatty acids in serum phospholipids: Omega-3 and omega- 6 fatty acids and the risk of prostate cancer. Int. J. Cancer 1997, 71, 545-551. [CrossRef]

90. Yang, W.; Sui, J.; Ma, Y.; Simon, T.G.; Petrick, J.L.; Lai, M.; McGlynn, K.A.; Campbell, P.T.; Giovannucci, E.L.; Chan, A.T.; et al. High dietary intake of vegetable or polyunsaturated fats is associated with reduced risk of hepatocellular carcinoma. Clin. Gastroenterol. Hepatol. 2020, 30, 779. [CrossRef]

91. Shin, A.; Cho, S.; Sandin, S.; Lof, M.; Oh, M.Y.; Weiderpass, E. Omega-3 and -6 fatty acid intake and colorectal cancer risk in Swedish women's lifestyle and health cohort. Cancer Res. Treat. 2020, 52, 848-854. [CrossRef]

92. Zhou, Y.; Wang, T.; Zhai, S.; Li, W.; Meng, Q. Linoleic acid and breast cancer risk: A meta-analysis. Public Health Nutr. 2016, 19, 1457-1463. [CrossRef] [PubMed]

93. Freedman, L.S.; Potischman, N.; Kipnis, V.; Midthune, D.; Schatzkin, A.; Thompson, F.E.; Troiano, R.P.; Prentice, R.; Patterson, R.; Carroll, R.; et al. A comparison of two dietary instruments for evaluating the fat-breast cancer relationship. Int. J. Epidemiol. 2006, 35, 1011-1021. [CrossRef] [PubMed]

94. Arab, L. Biomarkers of fat and fatty acid intake. J. Nutr. 2003, 133 (Suppl. 3), 925S-932S. [CrossRef]

95. Wu, J.H.; Lemaitre, R.N.; King, I.B.; Song, X.; Psaty, B.M.; Siscovick, D.S.; Mozaffarian, D. Circulating omega-6 polyunsaturated fatty acids and total and cause-specific mortality: The cardiovascular health study. Circulation 2014, 130, 1245-1253. [CrossRef] [PubMed]

96. Farvid, M.S.; Ding, M.; Pan, A.; Sun, Q.; Chiuve, S.E.; Steffen, L.M.; Willett, W.C.; Hu, F.B. Dietary linoleic acid and risk of coronary heart disease: A systematic review and meta-analysis of prospective cohort studies. Circulation 2014, 130, 1568-1578. [CrossRef]

97. Harris, W.S.; Poston, W.C.; Haddock, C.K. Tissue n-3 and n-6 fatty acids and risk for coronary heart disease events. Atherosclerosis 2007, 193,1-10. [CrossRef]

98. Lu, X.; Yu, H.; Ma, Q.; Shen, S.; Das, U.N. Linoleic acid suppresses colorectal cancer cell growth by inducing oxidant stress and mitochondrial dysfunction. Lipids Health Dis. 2010, 9, 106. [CrossRef]

99. Dommels, Y.E.; Haring, M.M.; Keestra, N.G.; Alink, G.M.; van Bladeren, P.J.; van Ommen, B. The role of cyclooxygenase in n-6 and n-3 polyunsaturated fatty acid mediated effects on cell proliferation, PGE(2) synthesis and cytotoxicity in human colorectal carcinoma cell lines. Carcinogenesis 2003, 24, 385-392. [CrossRef]

100. Zhang, C.; Yu, H.; Shen, Y.; Ni, X.; Shen, S.; Das, U.N. Polyunsaturated fatty acids trigger apoptosis of colon cancer cells through a mitochondrial pathway. Arch. Med. Sci. 2015, 11, 1081-1094.

101. Colquhoun, A.; Schumacher, R.I. Gamma-linolenic acid and eicosapentaenoic acid induce modifications in mitochondrial metabolism, reactive oxygen species generation, lipid peroxidation and apoptosis in walker 256 rat carcinosarcoma cells. Biochim. Biophys. Acta 2001, 1533, 207-219. [CrossRef]

102. Colquhoun, A. Gamma-linolenic acid alters the composition of mitochondrial membrane subfractions, decreases outer mitochondrial membrane binding of hexokinase and alters carnitine palmitoyl transferase $\mathrm{i}$ properties in the walker 256 rat tumour. Biochim. Biophys. Acta 2002, 1583, 74-84. [CrossRef]

103. Xu, Y.; Qi, J.; Yang, X.; Wu, E.; Qian, S.Y. Free radical derivatives formed from cyclooxygenase-catalyzed dihomo-gamma-linolenic acid peroxidation can attenuate colon cancer cell growth and enhance 5-fluorouracil's cytotoxicity. Redox Biol. 2014, 2, 610-618. [CrossRef] [PubMed] 
104. Abel, S.; Riedel, S.; Gelderblom, W.C. Dietary pufa and cancer. Proc. Nutr. Soc. 2014, 73, 361-367. [CrossRef] [PubMed]

105. Tapiero, H.; Ba, G.N.; Couvreur, P.; Tew, K.D. Polyunsaturated fatty acids (pufa) and eicosanoids in human health and pathologies. Biomed. Pharmacother. 2002, 56, 215-222. [CrossRef]

106. Mohrhauer, H.; Holman, R.T. The effect of dose level of essential fatty acids upon fatty acid composition of the rat liver. J. Lipid Res. 1963, 4, 151-159.

107. Hussein, N.; Ah-Sing, E.; Wilkinson, P.; Leach, C.; Griffin, B.A.; Millward, D.J. Long-chain conversion of [13C]linoleic acid and alpha-linolenic acid in response to marked changes in their dietary intake in men. J. Lipid Res. 2005, 46, 269-280. [CrossRef]

108. Hodge, A.M.; Simpson, J.A.; Gibson, R.A.; Sinclair, A.J.; Makrides, M.; O’Dea, K.; English, D.R.; Giles, G.G. Plasma phospholipid fatty acid composition as a biomarker of habitual dietary fat intake in an ethnically diverse cohort. Nutr. Metab. Cardiovasc. Dis. 2007, 17, 415-426. [CrossRef]

(C) 2020 by the authors. Licensee MDPI, Basel, Switzerland. This article is an open access article distributed under the terms and conditions of the Creative Commons Attribution (CC BY) license (http://creativecommons.org/licenses/by/4.0/). 